\title{
Utility of bronchoalveolar lavage in the management of immunocompromised patients presenting with lung infiltrates
}

\author{
Randall Choo ${ }^{1,4} \mathbb{D}$, Naser Salman Hamza Naser ${ }^{2,4}$, Nivedita Vikas Nadkarni ${ }^{3}$ and Devanand Anantham ${ }^{4 *}$
}

\begin{abstract}
Background: Bronchoalveolar lavage (BAL) is utilized for diagnosing lung infiltrates in immunocompromised. There is heterogeneity in the data and reported diagnostic yields range from 26 to $69 \%$. Therefore, selection criteria for BAL to maximize yield and minimize complications are unclear. Objectives of this study were to determine the diagnostic yield and complication rate of BAL in immunocompromised patients presenting with lung infiltrates, and identify factors impacting these outcomes. Exploratory aims included characterization of pathogens, rate of treatment modification and mortality.

Methods: Retrospective study from January 2012 to December 2016. Patients on mechanical ventilation were excluded. Positive diagnostic yield was defined as confirmed microbiological or cytological diagnosis.

Results: A total of 217 patients were recruited (70.1\% male and mean age: $51.7 \pm 14.6$ years). Diagnostic yield was $60.8 \%$ and complication rate 14.7\%. Complications (hypoxemia and endobronchial bleeding) were all sell-limiting. Treatment modification based on BAL results was $63.3 \%$. In $97.0 \%$ an infectious aetiology was identified. HIV infection (OR 5.304, 95\% Cl 1.611-17.458, $p=0.006$ ) and severe neutropenia (OR 4.253, 95\% Cl 1.288-14.045, $p=0$. 018) were associated with positive yield. Leukemia (OR $0.317,95 \% \mathrm{Cl} 0.102-0.982, p=0.047$ ) was associated with lower yield. No factors impacted complication rate. Overall mortality (90-day) was $17.5 \%$ and in those with hematologic malignancy, it was 28.3\%.
\end{abstract}

Conclusion: BAL retains utility in diagnosis of immunocompromised patients with lung infiltrates. However, patients with hematologic malignancy have a high mortality and alternative sampling should be considered because of poor results with BAL.

Trial registration: ClinicalTrials.gov identifier NCT01374542. Registered June 16, 2011.

Keywords: Bronchoalveolar lavage, Flexible bronchoscopy, Immunocompromised, Lung infiltrates

\section{Introduction}

Lung infiltrates cause significant morbidity and mortality in immunocompromised patients $[1,2]$. However, this is a heterogeneous group with various aetiology of underlying immunosuppression. The Infectious Diseases Society of America 2013 guidelines has included in its definition of highly immunocompromised patients the following groups: combined immunodeficiency disorder,

\footnotetext{
* Correspondence: anantham.devanand@singhealth.com.sg

${ }^{4}$ Department of Respiratory and Critical Care Medicine, Singapore General Hospital, Academia Building Level 3, 20 College Road, S169856, Singapore, Singapore

Full list of author information is available at the end of the article
}

chemotherapy for cancer, $\leq 2$ months post-solid organ transplantation, human immunodeficiency virus (HIV) infection with a CD4 T-lymphocyte count $<200$ cells/ $\mathrm{mm}^{3}$, daily corticosteroid treatment with a dose $\geq 20 \mathrm{mg}$ of prednisone or equivalent for $\geq 14$ days and use of biologic immune modulators such as tumor necrosis factor-alpha blockers or rituximab [3]. Moreover in clinical practice, patients with hematological malignancies or neutropenia and those on steroid-sparing immunosuppressants are also considered immunocompromised.

Despite this heterogeneity of underlying etiology, the majority of these patients with lung infiltrates present in similar manner with cough, fever and dyspnea [4]. 
Empiric treatment is not without risks including adverse drug reactions, inadequacy of therapy and development of antimicrobial resistance. Therefore, obtaining a confirmed diagnosis is essential since the therapeutic paradigm varies widely depending on the cause of the lung infiltrates. In addition, early diagnosis has been associated with improved survival, with data reporting confirmed diagnosis within 5 days having a lower mortality compared to later diagnosis ( $32 \%$ vs. $51 \%, p=0.024$ ) [1].

Flexible bronchoscopy is commonly used for investigating lung infiltrates because it facilitates collection of microbiological and cytological samples via bronchoalveolar lavage (BAL) and can be performed in an ambulatory setting [5]. Complications of this procedure include hypoxemia and myocardial ischemia [5]. Data on diagnostic yield of BAL in immunocompromised patients presenting with lung infiltrates range from 26 to 69\%; and complication rates range from 1 to $52 \%$ (Table 1 ). There is marked heterogeneity in the data both in inclusion criteria and study design. This makes it challenging to draw definite conclusions on which patients are most likely to benefit from BAL and on the prognosis of the various groups when categorized according to underlying cause of immunosuppression. In addition, there is limited data from countries where tuberculosis is endemic.
The primary objective of this study was to determine the diagnostic yield of BAL in immunocompromised patients presenting with lung infiltrates. Patients who have already progressed to respiratory failure requiring mechanical ventilation have a mortality rate of nearly $>50 \%$ and need to be considered separately [1]. This population was beyond the scope of our study. Additionally, we aimed to determine the incidence of complications of BAL and identify factors associated with either higher diagnostic yields or lower complication rates. Exploratory aims include characterization of commonly isolated pathogens, the rate of post-procedure treatment modification as an indicator of clinical utility, as well as post-procedure 30 and 90-day mortality. Post-procedure treatment modification reflects the true value of the procedure since some microbiological findings may be of non-pathogenic commensals while other results may not be amendable to clinical intervention. Identification of such data will optimize patient selection, allowing endoscopists to counsel patients and recommend alternative diagnostic modalities for those with low likelihood of successful diagnosis or at high risk of complications.

\section{Materials and methods}

This retrospective cross-sectional study evaluated immunocompromised patients with radiographic evidence

Table 1 Diagnostic yield and complication rate of BAL in immunocompromised patients presenting with lung infiltrates from a PubMed search since 2000

\begin{tabular}{|c|c|c|c|c|c|}
\hline & Study design & Inclusion criteria & BAL Procedures (patient number) & Diagnostic yield \% & Complication rate \\
\hline Reichenberger et al., 2001 [16] & Retrospective & Post renal transplant & $91(71)$ & $69 \%(63 / 91)$ & - \\
\hline Hohenadel et al., 2001 [13] & Retrospective & Hematology patients & $95(95)$ & $65 \%(62 / 95)$ & $16 \%(15 / 95)$ \\
\hline Rano et al., 2001 [17] & Prospective & Mixed etiology but HIV patients excluded & $135(200)$ & $51 \%(68 / 135)$ & $2 \%(3 / 135)$ \\
\hline Taggart et al., 2002 [18] & Retrospective & HIV patients & $216(174)$ & $50 \%(108 / 216)$ & - \\
\hline Danés et al., 2002 [9] & Prospective & Mixed aetiology including HIV & $134(241)$ & $52 \%(70 / 134)$ & - \\
\hline Jain et al., 2004 [19] & Prospective & Mixed etiology, HIV excluded & $99(104)$ & $38 \%(48 / 125)$ & $14 \%(8 / 59)$ \\
\hline Bissinger et al., 2005 [20] & Retrospective & Hematology patients & $95(77)$ & $56 \%(53 / 95)$ & - \\
\hline Peikert et al., 2005 [14] & Retrospective & Neutropenia & $35(35)$ & $49 \%(17 / 35)$ & $9 \%(3 / 35)$ \\
\hline Hofmeister et al., 2006 [21] & Retrospective & Hematopoietic stem cell transplant & $91(78)$ & $49 \%(45 / 91)$ & $8 \%(7 / 91)$ \\
\hline Vélez et al., 2007 [10] & Prospective & Mixed aetiology including HIV & $109(101)$ & $49 \%(60 / 122)$ & - \\
\hline Boersma et al., 2007 [22] & Prospective & Hematological malignancy & $35(32)$ & $26 \%(9 / 35)$ & - \\
\hline Burger, 2007 [23] & Retrospective & Hematopoietic stem cell transplant & $27(21)$ & $52 \%(14 / 27)$ & $52 \%(11 / 21)$ \\
\hline Cordani et al., 2008 [24] & Prospective & Hematological malignancy & $25(24)$ & $44 \%(11 / 25)$ & - \\
\hline Hummel et al., 2008 [25] & Retrospective & Hematological malignancy & $246(199)$ & $48 \%(118 / 246)$ & $1 \%(3 / 249)$ \\
\hline Shannon et al., 2010 [26] & Retrospective & Hematopoietic stem cell transplant & $598(501)$ & $55 \%(329 / 598)$ & $12 \%(74 / 598)$ \\
\hline Sampsonas et al., 2011 [15] & Prospective & Mixed etiology but HIV patients excluded & $284(284)$ & $34 \%(96 / 284)$ & $4 \%(10 / 284)$ \\
\hline Kottmann et al., 2011 [27] & Retrospective & Mixed etiology & $190(190)$ & $56 \%(106 / 190)$ & - \\
\hline Gilbert et al., 2012 [28] & Retrospective & Hematopoietic stem cell transplant & $145(144)$ & $53 \%(77 / 145)$ & $30 \%(49 / 162)$ \\
\hline Brownback et al., 2013 [11] & Retrospective & Mixed aetiology including HIV & $150(133)$ & $52.5 \%(79 / 150)$ & $7 \%(11 / 150)$ \\
\hline Kim et al., 2015 [29] & Retrospective & Hematologic malignancy & $206(187)$ & $65 \%(134 / 206)$ & - \\
\hline Svensson et al., 2017 [30] & Retrospective & Hematologic malignancy & $151(133)$ & $39 \%(59 / 151)$ & $13 \%(20 / 151)$ \\
\hline Sakata et al., 2017 [31] & Retrospective & Hematopoietic stem cell transplant & $179(125)$ & $40 \%(71 / 179)$ & - \\
\hline
\end{tabular}


of lung infiltrates who underwent BAL from January 2012 to December 2016 at a tertiary acute care hospital in Singapore. Inclusion criteria was (1) immunocompromised patients, $(2)$ new ( $\leq 1$ month) pulmonary infiltrates on chest radiograph or computed tomography scan, and (3) undergoing flexible bronchoscopy with BAL in an ambulatory setting. Immunocompromised patients were defined according to the Infectious Diseases Society of America 2013 guidelines as highly immunosuppressed or if they had either ongoing haematological malignancy, neutropenia or steroid-sparing immunosuppressant therapy [3]. Neutropenia severity was categorized based on absolute neutrophil count from mild (1000-1499 per microliter), moderate (500-999 per microliter) and severe $(<500$ per microliter). Exclusion criteria comprised BAL performed in an ICU setting on mechanically ventilated patients, due to differences in procedure such as bronchoscope intubation via an endotracheal tube. Prognosis is also different and poor when the patient has progressed to respiratory failure [1]. Patients who underwent transbronchial lung biopsies or other forms of bronchoscopic sampling were also excluded to avoid introduction of confounding factors.

Data was extracted from a bronchoscopy database that prospectively collects, via endoscopists' reports, all bronchoscopy details performed at the hospital endoscopy centre. This ensured integrity and completeness of data collection over the study period. Data was rendered non-identifiable with removal of patient's name, identification card number and date of procedure. Chest computed tomography $(\mathrm{CT})$ scans were interpreted by a radiologist and consultant pulmonologist and the predominant abnormalities characterized according to the following categories: consolidation, ground glass opacities, tree-in-bud appearance, reticular infiltrates, nodular infiltrates and cavitation. Institutional review board approval was obtained (SingHealth Centralised Institutional Review Board, reference number: 2011/350/C) and ClinicalTrials.gov identifier is NCT01374542. Waiver of consent was provided by SingHealth Centralised Institutional Review Board.

\section{Procedural details}

Bronchoscopy was performed using an Olympus BF-1 T160 (Olympus, Tokyo, Japan) bronchoscope that has an outer diameter of $6.0 \mathrm{~mm}$ with a $2.8 \mathrm{~mm}$ working channel. All procedures were performed under moderate sedation using a combination of fentanyl and midazolam. BAL was obtained from the bronchopulmonary segment corresponding to $\mathrm{CT}$ scan findings for focal infiltrates while the right middle lobe or lingular was preferred in the cases with diffuse infiltrates. BAL samples were sent for standardized investigations consisting of cytology and microbiological analysis.
Microscopy for bacteria was performed with Gram stain, acid fast bacilli with Ziehl-Neelsen stain and Pneumocystis jirovecii with Gomori methenamine silver. This was followed by bacterial, fungal and mycobacterial cultures. Polymerase chain reaction testing was performed for Mycobacterium tuberculosis (TB-Protec) and respiratory viruses: influenza, parainfluenza, respiratory syncytial virus, coronavirus, adenovirus, rhinovirus and metapneumovirus. Cytomegalovirus detected by BAL fluid antigen assay or cell-based virus isolation was considered pathogenic only in the presence of either intracellular inclusion bodies on cytology or concomitant positive serum antigenemia. Galactomannan antigen was performed via enzyme-linked immunosorbent assay.

\section{Outcome measures}

Primary outcome was diagnostic yield as defined as the number of BAL with a positive diagnostic study divided by the total number of patients. A positive study was defined as either a confirmed diagnosis on cytology or microbiology. Post-BAL treatment modification was considered positive if treatment was documented to be initiated, escalated or discontinued in response to diagnostic BAL findings and if treatment change was in keeping with BAL findings. Patients were followed-up for a minimum of 6 months. Sub-group analysis was performed according to underlying cause of immunosuppression and patients were classified into 3 groups: HIV positive patients, ongoing hematological malignancy and others (HIV negative, non-hematologic malignancy).

Complications were considered associated with bronchoscopy if they occurred peri-procedurally or within $24 \mathrm{~h}$ after the patient underwent the procedure. Complication rate was calculated as the number of procedures with complications divided by the total number of procedures performed. Complications were classified into six categories using Common Terminology Criteria for Adverse Events (CTCAE) definitions/severity of pneumothorax, airway bleeding, hypoxia, hypotension and requirement for escalation of level of care [6].

\section{Statistical analysis}

Statistical analyses were performed using statistical software SPSS (IBM Corp. Released 2016. IBM SPSS Statistics for Windows, Version 24.0. Armonk, NY: IBM Corp). Findings were considered statistically significant for all analyses with $p$-value $<0.05$. Continuous variables were summarized using mean (standard deviation, SD) or median (interquartile range, IQR) and categorical variables were summarized using frequency (\%). Fisher's exact test and Student's $t$ test or Mann-Whitney U test as appropriate were used to compare categorical and continuous variables respectively. Secondary outcomes were analyzed using logistic regression. Factors with 
unadjusted odds ratios from univariate logistic regression that satisfied the criteria of $p$-value $<0.2$ were included in multivariable logistic regression analysis to determine the adjusted odds ratios of factors significantly associated with diagnostic yield and complication rate.

\section{Results}

Flexible bronchoscopy with BAL was performed on 217 immunocompromised patients between January 2012 to December 2016. One hundred fifty-two patents (70.1\%) were male and the mean age was $51.7 \pm 14.6$ years. Fifty-nine patients (27.2\%) were HIV positive amongst whom 3 had concurrent lymphoma with 2 receiving ongoing chemotherapy. All 59 were analyzed under the HIV category because that was the underlying cause of immunosuppression. A further 92 patients (92/217; 42.4\%) had an ongoing hematologic malignancy: 55 with leukemia, 28 with lymphoma, 6 with myelodysplastic syndrome and 3 with multiple myeloma. Among patients with hematologic malignancy, 75 (75/92; 81.5\%) had received chemotherapy within the preceding 6 months, 60 patients $(60 / 92 ; 65.2 \%)$ were neutropenic at the time of presentation of pulmonary infiltrates and 19 (19/92; 20.7\%) had received hematopoietic stem cell transplants. The remaining 66 (66/217; 30.4\%) HIV negative, non-hematologic malignancy patients had immunosuppression due to other causes: of whom 27 received chemotherapy for solid organ malignancies, 15 had solid organ transplants, 38 had received steroid-sparing immunosuppressants and 14 had received high dose corticosteroid therapy.

Fever was the most common presenting symptom $(67.3 \%, 146 / 217)$ followed by cough $(53.5 \%, 116 / 217)$ and dyspnea $(36.4 \%, 79 / 217)$. Median duration of symptoms was 14 days (IQR 8-22.5). Most patients (88.5\%, $192 / 217$ ) received empiric antibiotics prior to bronchoscopy for a median duration of 5 days (IQR 2-10). CT chest scan was obtained in $83.4 \%(181 / 217)$ of patients, with consolidation being the most common finding $(66.9 \%, 121 / 181)$ followed by ground glass opacities $(51.3 \%, 93 / 181)$. CT scans were performed with a median of 3 days (IQR 2, 5) prior to BAL procedure. Patient characteristics are presented in Table 2. Median duration of bronchoscopy was $10 \mathrm{~min}$ (IQR 10-15) and the following sedation was used: median midazolam $2.50 \mathrm{mg}$ (IQR 2.00-3.50) and fentanyl 50 microgram (IQR 2550). The median volume of BAL fluid instilled was 120 $\mathrm{mL}$ (IQR $100-140$ ) and $>30 \%$ of instilled volume was retrieved in $91 \%$ of cases $(152 / 167)$.

Overall diagnostic yield for this study was $60.8 \%$ (132/ 217). Post-procedure treatment modification based on BAL results was $63.3 \%$ (84/132). Majority of positive BAL yielded infectious agents $(97.0 \%, 128 / 132)$ with 37 cases of Pneumocystis jirovecii, 13 Mycobacteria tuberculosis and 12 rhinovirus. Cytomegalovirus was found in 16 cases but no inclusion bodies were identified on cytology. Table 3 shows all BAL microbiological results. Galactomannan testing was also positive in 31 cases, with $\geq 0.5$ antigen index considered positive. Non-infectious causes of pulmonary infiltrates was found in 4 cases based on cytology and clinical/radiological presentation: eosinophilic pneumonia, squamous cell carcinoma, lung adenocarcinoma and drug-induced pneumonitis. Differences in characteristics of patients with positive and negative BAL are outlined in Table 4.

In multivariable logistic regression analysis, factors significantly associated with higher diagnostic yield included HIV infection (adjusted OR 5.304, 95\% CI 1.61117.458, $p=0.006$ ), severe neutropenia (adjusted OR $4.253,95 \%$ CI $1.288-14.045, p=0.018$ ) and presence of cavitatory lesions on chest CT scan (adjusted OR 3.824, 95\% CI 0.877-16.680, $p=0.074$ ). In addition, leukaemia as an underlying cause of immunosuppression was significantly associated with lower diagnostic yield (adjusted OR 0.317, 95\% CI 0.102-0.982, $p=0.047$ ) (See supplementary materials in Appendix 1). In univariate analysis, haematological malignancy (unadjusted OR $0.501,95 \%$ CI $0.288-0.871, p=0.014)$ and ongoing chemotherapy at the time of the scope (unadjusted OR $0.350,95 \%$ CI $0.199-0.616, p<0.001)$ had a lower diagnostic yield (Appendix 1).

Overall complication rate for this study was 14.7\% (32/ $217)$ with $94 \%(30 / 32)$ attributable to self-limiting hypoxemia that required supplemental oxygen therapy temporarily (CTCAE 2). The remaining two cases were of endobronchial bleeding that did not require further endoscopic intervention (CTCAE 1). Both patients were thrombocytopenic with platelet counts of 27,000 per microliter and 126,000 per microliter. No patients required intubation or escalation of care. Post-procedure 30-day and 90-day mortality was $10.6 \%$ (23/217) and $17.5 \%(38 / 217)$ respectively. Patients who suffered complications had significantly higher median Charlson comorbidity index (median 5, IQR 3-7) compared to those who did not suffer complications (median 4, IQR 3-6; $p$ $=0.011$ ) [7]. Univariate logistic regression analysis for complication rate found dyspnea during disease presentation to be significantly associated with increased complications (unadjusted OR 2.508, 95\% CI 1.169-5.382, $p$ $=0.018$ ). Multivariable logistic regression analysis found no factors significantly associated with complication rate (See supplementary material in Appendix 2).

\section{Subgroup analyses}

Diagnostic yield of BAL in HIV patients was 79.7\% (47/ 59) of which the majority of positive diagnoses was of Pneumocystis jirovecii $(70.2 \%, 33 / 47)$. Other diagnoses 
Table 2 Patient characteristics

\begin{tabular}{|c|c|}
\hline & $\mathrm{n}(\%)$ \\
\hline Total number of patients & 217 \\
\hline Mean age in years & $51.7 \pm 14.6$ \\
\hline Male gender & $152(70.0 \%)$ \\
\hline Current Smokers & $27(12.4 \%)$ \\
\hline \multicolumn{2}{|l|}{ Cause of immunosuppression: } \\
\hline HIV/ AIDS & $59(27.2 \%)$ \\
\hline High dose corticosteroid & $16(7.4 \%)$ \\
\hline Steroid-sparing immunosuppressive medication & $44(20.3 \%)$ \\
\hline Solid organ transplant & $15(6.9 \%)$ \\
\hline Bone marrow transplant & $33(15.7 \%)$ \\
\hline Hematologic malignancy & $95(43.8 \%)$ \\
\hline Leukemia & $55(25.3 \%)$ \\
\hline Lymphoma & $28(12.9 \%)$ \\
\hline Myelodysplastic syndrome & $6(2.8 \%)$ \\
\hline Multiple myeloma & $3(1.4 \%)$ \\
\hline Chemotherapy & $104(47.9 \%)$ \\
\hline Neutropenia & $72(33.2 \%)$ \\
\hline \multicolumn{2}{|l|}{ Co-morbidities: } \\
\hline Cardiac (e.g. heart failure, ischemic heart disease) & $9(4.1 \%)$ \\
\hline Pulmonary (e.g. asthma, chronic obstructive pulmonary disease) & $23(10.6 \%)$ \\
\hline Hepatic (e.g. chronic hepatitis, cirrhosis) & $21(9.7 \%)$ \\
\hline Renal (e.g. chronic kidney disease) & $13(6.0 \%)$ \\
\hline \multicolumn{2}{|l|}{ Treatment at the time of BAL: } \\
\hline Antibiotics & $192(88.5 \%)$ \\
\hline Median duration, days (IQR) & $5(2-10)$ \\
\hline Antivirals & $103(47.5 \%)$ \\
\hline Antifungals & $83(38.2 \%)$ \\
\hline \multicolumn{2}{|l|}{ Clinical presentation: } \\
\hline Fever & $146(67.3 \%)$ \\
\hline Cough & $116(53.5 \%)$ \\
\hline Dyspnea & $79(36.4 \%)$ \\
\hline Pleurisy & $19(8.8 \%)$ \\
\hline Median symptom duration, days (IQR) & $14(8-22.5)$ \\
\hline Radiologic presentation on CT: & $n=181$ \\
\hline Consolidation & $121(66.9 \%)$ \\
\hline Ground glass opacities & $93(51.3 \%)$ \\
\hline Nodules & $63(34.8 \%)$ \\
\hline Cavitation & $20(11.0 \%)$ \\
\hline Tree-in-bud appearance & $18(9.9 \%)$ \\
\hline Reticular pattern & $11(6.1 \%)$ \\
\hline
\end{tabular}

included 4 cases of Mycobacteria tuberculosis, 4 rhinovirus and 3 Aspergillus species. Despite the high diagnostic yield, only $40.4 \%(19 / 47)$ of BAL results in HIV directly impacted patient management. Complication rate was $20.3 \%(12 / 59)$ all of which was attributable to hypoxemia requiring supplemental oxygen. Post-procedure 30-day and 90-day mortality was $1.7 \%$ $(1 / 59)$ and $6.8 \%(4 / 59)$ respectively. 
Table 3 BAL microbiology results

\begin{tabular}{|c|c|}
\hline & n (\%) \\
\hline \multicolumn{2}{|l|}{ Bacterial } \\
\hline Total & 43 \\
\hline Mycobacterium tuberculosis & $13(30.2 \%)$ \\
\hline Pseudomonas aeruginosa & $8(18.6 \%)$ \\
\hline Klebsiella spp. & $5(11.6 \%)$ \\
\hline Enterococcus spp. & $4(9.3 \%)$ \\
\hline Stentotrophomonas maltophilia & $4(9.3 \%)$ \\
\hline Staphylococcus aureus & $2(4.7 \%)$ \\
\hline Acinetobacter baumannii & $1(2.3 \%)$ \\
\hline Escherichia coli & $1(2.3 \%)$ \\
\hline Mycobacterium abscessus & $1(2.3 \%)$ \\
\hline Mycobacterium avium & $1(2.3 \%)$ \\
\hline Nocardia sp. & $1(2.3 \%)$ \\
\hline Streptococcus pneumoniae & $1(2.3 \%)$ \\
\hline Streptococcus anginosus & $1(2.3 \%)$ \\
\hline \multicolumn{2}{|l|}{ Fungal Microscopy/Culture } \\
\hline Total & 51 \\
\hline Pneumocystis jirovecii & $37(72.5 \%)$ \\
\hline Aspergillus spp. & $10(19.6 \%)$ \\
\hline Cryptococcus spp. & $3(5.9 \%)$ \\
\hline Phaeoacremonium spp. & $1(2.0 \%)$ \\
\hline \multicolumn{2}{|l|}{ Viral } \\
\hline Total & 64 \\
\hline Cytomegalovirus & $16(25.0 \%)$ \\
\hline Rhinovirus & $12(18.8 \%)$ \\
\hline Coronavirus & $9(14.1 \%)$ \\
\hline Parainfluenza & $9(14.1 \%)$ \\
\hline Influenza & $7(10.9 \%)$ \\
\hline Respiratory syncytial virus & $7(10.9 \%)$ \\
\hline Adenovirus & $3(4.7 \%)$ \\
\hline Metapneumovirus & $1(1.6 \%)$ \\
\hline
\end{tabular}

In non-HIV, hematologic malignancy patients diagnostic yield was $51.1 \%$ (47/92) and of these $70.2 \%$ (33/47) of cases impacted patient management with treatment modification. Isolated pathogens included 8 cases of parainfluenza virus, 5 Pseudomonas aeruginosa, 4 rhinovirus, 4 respiratory syncytial virus, 3 Mycobacterium tuberculosis, 3 Klebsiella species and 3 coronavirus. Complication rate was $10.9 \%$ (10/92), while post-procedure 30-day and 90-day mortality was $17.4 \%$ $(16 / 92)$ and $28.3 \%(26 / 92)$ respectively. Mortality rate was significantly higher for non-HIV, hematologic malignancy patients than for HIV and for non-HIV, non-hematologic malignancy groups.

In non-HIV, non-hematologic malignancy patients diagnostic yield was $57.6 \%$ (38/66), with $84.2 \%(32 / 38)$ of these resulting in modification of therapy. Pathogens included 6 cases of Mycobacterium tuberculosis, 5 human coronavirus, 5 Aspergillus species, 4 Pneumocystis jirovecii, 4 rhinovirus and 3 cases of Pseudomonas aeruginosa. Complication rate was $15.2 \%$ (10/66) and post-procedure 30-day and 90-day mortality was $9.1 \%$ $(6 / 66)$ and $12.1 \%(8 / 66)$ respectively. Test of proportions indicated that mortality rate was significantly different in at least one category (HIV patients, non-HIV hematologic malignancy patients or non-HIV, non-hematologic malignancy patients) compared to the others $(p=0.008)$.

\section{Discussion}

The diagnostic yield of BAL in immunocompromised patients presenting with lung infiltrates in an ambulatory setting was $60.8 \%$ and in the majority of cases, the positive BAL findings impacted clinical management. Infectious etiologies accounted for $97 \%$ of the positive diagnoses which reinforces current clinical practice of early use of empiric antibiotics. In addition, our study found no impact of prior anti-microbial therapy or duration of antibiotics on diagnostic yield. The mismatch between positive yield and post-BAL result treatment modification may be attributable to the fact that $40.5 \%$ $(64 / 158)$ of pathogens detected were respiratory viruses for which therapeutic options were limited. In addition, in none of the 16 isolates of cytomegalovirus was there inclusion bodies detected in the corresponding cytology. This raises doubts over the pathogenic nature of the cytomegalovirus isolates. Cases where the BAL cytomegalovirus isolate was the only finding (including no antigenemia) were not labelled as positive diagnostic yield. There were $17.1 \%$ (37/217) cases of Pneumocystis jirovecii, $6.0 \%(13 / 217)$ cases of tuberculosis, $4.6 \%$ (10/ 217) cases of Aspergillosis and 3.7\% (8/217) cases of Pseudomonas infection. In addition, in $14.3 \%(31 / 217)$ BAL Galactomannan was positive.

We also showed differences in the diagnostic yield between different groups based on causes of underlying immunosuppression. HIV patients had the highest diagnostic yield and the majority of positive Pneumocystis jirovecii results identified were in this group. It also meant that post-BAL treatment modification was the lowest in this group because Pneumocystis pneumonia was often the clinical diagnosis and appropriate empiric treatment had already been commenced. There was also a trend towards increased risk of post procedure hypoxia in HIV patients which endoscopists should note with respect to ensuring appropriate post-procedure monitoring. Previous data on HIV patients showed a diagnostic yield of $50-60 \%$ [8], and mixed groups with HIV patients showed yields of 49 to $52.5 \%$ [9-11].

In contrast, the diagnostic yield was lower in patients with hematologic malignancy, especially those with leukaemia. There are possible explanations for this. 
Table 4 Factors impacting BAL diagnostic yield $\left(^{*} p<0.05\right)$

\begin{tabular}{|c|c|c|c|}
\hline & Negative BAL n (\%) & Positive BAL n (\%) & p-value \\
\hline Total & 85 (39.2\%) & $132(60.8 \%)$ & \\
\hline Male gender & $54(63.5 \%)$ & $98(74.2)$ & 0.098 \\
\hline Mean age in years $\pm S D$ & $52.4 \pm 14.6$ & $51.3 \pm 14.6$ & 0.588 \\
\hline Current smokers & $10(11.8 \%)$ & $17(12.9 \%)$ & 1.000 \\
\hline \multicolumn{4}{|l|}{ Cause of immunosuppression: } \\
\hline HIV/ AIDS & $12(14.1 \%)$ & $47(35.6 \%)$ & $0.001^{*}$ \\
\hline High dose corticosteroids & $8(9.4 \%)$ & $8(6.1 \%)$ & 0.428 \\
\hline Steroid-sparing immunosuppressive medication & $17(20.0 \%)$ & $27(20.5 \%)$ & 1.000 \\
\hline Hematologic malignancy & $46(54.1 \%)$ & $49(37.1 \%)$ & $0.017^{*}$ \\
\hline Leukemia & $30(35.3 \%)$ & 25 (18.9\%) & $0.010^{*}$ \\
\hline Lymphoma & $14(16.5 \%)$ & $17(12.9 \%)$ & 0.552 \\
\hline Myelodysplastic & $2(2.4 \%)$ & $4(3.0 \%)$ & 1.000 \\
\hline Multiple myeloma & $0(0 \%)$ & $3(2.3 \%)$ & 0.282 \\
\hline Chemotherapy & $54(63.5 \%)$ & $50(37.9 \%)$ & $<0.001^{*}$ \\
\hline Neutropenia & $32(37.6 \%)$ & $40(21.6 \%)$ & 0.302 \\
\hline 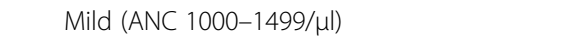 & $8(9.6 \%)$ & $4(3.1 \%)$ & 0.127 \\
\hline 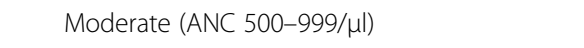 & $7(8.4 \%)$ & $6(4.6 \%)$ & \\
\hline 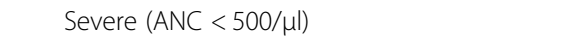 & $16(19.3 \%)$ & $29(22.1 \%)$ & \\
\hline \multicolumn{4}{|l|}{ Clinical presentation: } \\
\hline Fever & $60(74.1 \%)$ & $86(65.6 \%)$ & 0.224 \\
\hline Cough & $38(46.9 \%)$ & $78(59.5 \%)$ & 0.089 \\
\hline Dyspnea & $26(32.1 \%)$ & $53(40.5 \%)$ & 0.244 \\
\hline Pleurisy & $7(8.6 \%)$ & $12(9.2 \%)$ & 1.000 \\
\hline Median symptom duration in days (IQR) & $15(8-66)$ & $19(11-65.5)$ & $0.017^{*}$ \\
\hline \multicolumn{4}{|l|}{ Treatment at the time of BAL: } \\
\hline Antibiotics & 75 (90.4\%) & $117(90.0 \%)$ & 1.000 \\
\hline Median duration antibiotics in days (IQR) & $7(4,10)$ & $6(3,11)$ & 0.477 \\
\hline Antifungals & $33(38.8 \%)$ & $50(37.9 \%)$ & 0.887 \\
\hline Antivirals & $43(50.6 \%)$ & $60(45.5 \%)$ & 0.488 \\
\hline \multicolumn{4}{|l|}{ Radiologic presentation on $C T(n=181)$ : } \\
\hline Consolidation & $44(54.3 \%)$ & $57(57.0 \%)$ & 0.764 \\
\hline Ground glass opacities & $42(51.9 \%)$ & $51(51.0 \%)$ & 1.000 \\
\hline Tree-in-bud appearance & $11(13.6 \%)$ & $7(7.0 \%)$ & 0.211 \\
\hline Reticular pattern & $3(3.7 \%)$ & $8(8.0 \%)$ & 0.350 \\
\hline Nodules & $32(39.5 \%)$ & $31(31.0 \%)$ & 0.273 \\
\hline Cavitation & $6(7.5 \%)$ & $14(14.0 \%)$ & 0.233 \\
\hline \multicolumn{4}{|c|}{ BAL segments: } \\
\hline Upper lobes & $44(51.8 \%)$ & $62(47.7 \%)$ & 0.579 \\
\hline Right middle lobe & $26(30.6 \%)$ & $32(24.6 \%)$ & 0.350 \\
\hline Lower lobes & $32(37.6 \%)$ & $53(40.8 \%)$ & 0.671 \\
\hline
\end{tabular}

Non-infective aetiology such as alveolar haemorrhage may be more prevalent in this group. BAL can only procure cytological and not histological specimens for analysis. Other conditions such as drug induced pneumonitis may not have pathognomonic findings and it may be difficult to establish a confirmed cause when it is 


\section{Appendix 1}

Table 5 Univariate and multiple logistic regression for diagnostic yield ( $\left.{ }^{*} p<0.05\right)$

\begin{tabular}{|c|c|c|c|c|}
\hline & $\begin{array}{l}\text { Univariate OR } \\
(95 \% \mathrm{Cl})\end{array}$ & $p$-value & $\begin{array}{l}\text { Multiple OR } \\
(95 \% \mathrm{Cl})\end{array}$ & $\overline{p \text {-value }}$ \\
\hline Male Gender & $1.655(0.918-2.983)$ & 0.094 & & \\
\hline Mean age in years & $0.995(0.976-1.014)$ & 0.586 & & \\
\hline Current smokers & $1.109(0.482-2.552)$ & 0.808 & & \\
\hline \multicolumn{5}{|l|}{ Cause of immunosuppression: } \\
\hline High dose corticosteroids & $0.621(0.224-1.723)$ & 0.360 & & \\
\hline HIV/ AIDS & $3.364(1.659-6.820)$ & $0.001^{*}$ & $5.304(1.611-17.458)$ & $0.006^{*}$ \\
\hline Steroid-sparing immunosuppressive medication & $1.029(0.522-2.029)$ & 0.935 & & \\
\hline Solid organ transplant & $0.963(0.330-2.811)$ & 0.946 & & \\
\hline Bone marrow transplant & $1.217(0.567-2.610)$ & 0.614 & & \\
\hline Hematologic malignancy & $0.501(0.288-0.871)$ & $0.014^{*}$ & & \\
\hline Leukemia & $0.428(0.230-0.798)$ & $0.008^{*}$ & $0.317(0.102-0.982)$ & $0.047^{*}$ \\
\hline Lymphoma & $0.750(0.348-1.614)$ & 0.461 & & \\
\hline Myelodysplastic & $1.297(0.232-7.240)$ & 0.767 & & \\
\hline Multiple myeloma & N.A. & N.A. & & \\
\hline Chemotherapy & $0.350(0.199-0.616)$ & $<0.001^{*}$ & & \\
\hline Neutropenia & $0.720(0.405-1.279)$ & 0.263 & & \\
\hline \multicolumn{5}{|l|}{ Severity (Reference no neutropenia) } \\
\hline Mild (ANC 1000-1500/Ml) & $0.283(0.081-0.984)$ & 0.047 & $0.249(0.42-1.460)$ & 0.123 \\
\hline 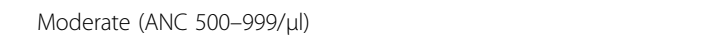 & $0.214(0.155-1.518)$ & 0.214 & $1.749(0.385-7.942)$ & 0.469 \\
\hline Severe $($ ANC $<500 / \mu l$ & $1.024(0.509-2.060)$ & 0.946 & $4.253(1.288-14.045)$ & $0.018^{*}$ \\
\hline \multicolumn{5}{|l|}{ Clinical Presentation: } \\
\hline Fever & $0.669(0.362-1.236)$ & 0.199 & & \\
\hline Cough & $1.665(0.952-2.912)$ & 0.074 & & \\
\hline Dyspnea & $1.437(0.803-2.574)$ & 0.222 & & \\
\hline Pleurisy & $1.066(0.402-2.830)$ & 0.898 & & \\
\hline Symptom duration & $1.021(1.001-1.042)$ & 0.039 & & \\
\hline \multicolumn{5}{|l|}{ Treatment at the time of BAL: } \\
\hline Antibiotics & $0.960(0.380-2.426)$ & 0.931 & & \\
\hline Duration of antibiotics & $0.995(0.964-1.028)$ & 0.784 & & \\
\hline Antifungals & $0.961(0.549-1.683)$ & 0.889 & & \\
\hline Antivirals & $0.814(0.471-1.405)$ & 0.460 & & \\
\hline \multicolumn{5}{|l|}{ Radiologic Presentation on $\mathrm{CT}$ : } \\
\hline Consolidation & $1.115(0.618-2.010)$ & 0.718 & & \\
\hline Ground glass opacities & $0.966(0.538-1.737)$ & 0.909 & & \\
\hline Tree-in-bud appearance & $0.479(0.177-1.298)$ & 0.148 & & \\
\hline Reticular pattern & $2.261(0.580-8.815)$ & 0.240 & & \\
\hline Nodules & $0.688(0.372-1.272)$ & 0.233 & & \\
\hline Cavitation & $2.031(0.743-5.554)$ & 0.167 & $3.824(0.877-16.680)$ & 0.074 \\
\hline \multicolumn{5}{|l|}{ Segments: } \\
\hline Upper lobes & $0.850(0.492-1.468)$ & 0.559 & & \\
\hline Right middle lobe & $0.741(0.403-1.364)$ & 0.335 & & \\
\hline Lower lobes & $1.140(0.650-1.998)$ & 0.647 & & \\
\hline Number of pulmonary segments sampled: $\geq 2$ (reference one segment) & $0.516(0.270-0.987)$ & $0.045^{*}$ & $0.347(0.125-0.965)$ & $0.043^{*}$ \\
\hline
\end{tabular}




\section{Appendix 2}

Table 6 Univariate and multiple logistic regression for risk of BAL complications ( ${ }^{*} p<0.05$ )

\begin{tabular}{|c|c|c|c|c|}
\hline & $\begin{array}{l}\text { Univariate OR } \\
(95 \% \mathrm{Cl})\end{array}$ & $p$-value & $\begin{array}{l}\text { Multiple OR } \\
(95 \% \mathrm{Cl})\end{array}$ & $p$-value \\
\hline Male gender & $2.029(0.793-5.194)$ & 0.140 & & \\
\hline Mean age in years & $0.986(0.961-1.011)$ & 0.263 & & \\
\hline Current smokers & $1.372(0.479-3.933)$ & 0.556 & & \\
\hline \multicolumn{5}{|l|}{ Cause of immunosuppression: } \\
\hline High dose corticosteroids & $0.366(0.47-2.869)$ & 0.338 & & \\
\hline HIV/ AIDS & $1.762(0.801-3.876)$ & 0.159 & & \\
\hline Steroid-sparing immunosuppressive medication & $1.120(0.450-2.789)$ & 0.808 & & \\
\hline Solid organ transplant & $1.491(0.396-5.610)$ & 0.554 & & \\
\hline Bone marrow transplant & $0.738(0.241-2.258)$ & 0.595 & & \\
\hline Hematologic malignancy & $0.535(0.240-1.192)$ & 0.126 & & \\
\hline Leukemia & $0.500(0.182-1.370)$ & 0.178 & & \\
\hline Lymphoma & $0.580(0.165-2.034)$ & 0.395 & & \\
\hline Myelodysplastic & N.A. & N.A. & & \\
\hline Multiple myeloma & $12.267(1.079-139.514)$ & $0.043^{*}$ & & \\
\hline Chemotherapy & $0.821(0.386-1.748)$ & 0.609 & & \\
\hline Neutropenia & $0.902(0.402-2.022)$ & 0.802 & & \\
\hline \multicolumn{5}{|l|}{ Severity (reference no neutropenia) } \\
\hline Mild (ANC 1000-1500/ml) & $1.848(0.464-7.372)$ & 0.384 & & \\
\hline Moderate (ANC 500-999/ml) & $0.462(0.057-3.736)$ & 0.469 & & \\
\hline Severe $($ ANC $<500 / \mathrm{ml})$ & $0.853(0.323-2.255)$ & 0.749 & & \\
\hline \multicolumn{5}{|l|}{ Comorbidities } \\
\hline Diabetes mellitus & $0.893(0.343-2.324)$ & 0.816 & & \\
\hline Cardiac & $0.714(0086-5.908)$ & 0.754 & & \\
\hline Pulmonary & $1.248(0.395-3.942)$ & 0.706 & & \\
\hline Hepatic & $1.412(0.442-4.505)$ & 0.560 & & \\
\hline Renal & $1.810(0.470-6.974)$ & 0.388 & & \\
\hline Charlson comorbidity index & $1.108(0.948-1.295)$ & 0.196 & & \\
\hline \multicolumn{5}{|l|}{ Clinical Presentation: } \\
\hline Fever & $1.184(0.515-2.722)$ & 0.690 & & \\
\hline Cough & $1.708(0.778-3.749)$ & 0.182 & & \\
\hline Dyspnea & $2.508(1.169-5.382)$ & $0.018^{*}$ & & \\
\hline Pleurisy & $0.639(0.140-2.911)$ & 0.563 & & \\
\hline Duration of symptoms & $1.005(0.988-1.022)$ & 0.592 & & \\
\hline \multicolumn{5}{|l|}{ Treatment at the time of BAL: } \\
\hline Antibiotics & N.A. & N.A. & & \\
\hline Duration of Antibiotics & $0.960(0.903-1.021)$ & 0.195 & & \\
\hline Antifungals & $0.489(0.208-1.146)$ & 0.100 & & \\
\hline Antivirals & $0.839(0.394-1.786)$ & 0.649 & & \\
\hline \multicolumn{5}{|l|}{ Radiologic presentation on $\mathrm{CT}$ : } \\
\hline Consolidation & $1.417(0.610-3.292)$ & 0.418 & & \\
\hline Ground glass opacity & $2.107(0.891-4.980)$ & 0.090 & & \\
\hline Tree-in-bud appearance & N.A. & N.A. & & \\
\hline
\end{tabular}


Table 6 Univariate and multiple logistic regression for risk of BAL complications ( $\left.{ }^{*} p<0.05\right)$ (Continued)

\begin{tabular}{|c|c|c|c|c|}
\hline & $\begin{array}{l}\text { Univariate OR } \\
(95 \% \mathrm{Cl})\end{array}$ & $p$-value & $\begin{array}{l}\text { Multiple OR } \\
(95 \% \mathrm{Cl})\end{array}$ & $p$-value \\
\hline Reticular pattern & $2.281(0.565-9.208)$ & 0.247 & & \\
\hline Nodules & $0.376(0.135-1.048)$ & 0.061 & $0.391(0.140-1.093)$ & 0.074 \\
\hline Cavitation & $0.596(0.130-2.728)$ & 0.505 & & \\
\hline Duration of procedure in minutes & $1.009(0.954-1.068)$ & 0.742 & & \\
\hline Dose of midazolam in milligram & $1.001(0.999-1.004)$ & 0.386 & & \\
\hline Dose of fentanyl in microgram & $1.002(0.987-1.018)$ & 0.792 & & \\
\hline \multicolumn{5}{|l|}{ Segments: } \\
\hline Upper lobes & $0.892(0.420-1.893)$ & 0.766 & & \\
\hline Right middle lobe & $0.725(0.295-1.779)$ & 0.482 & & \\
\hline Lower lobes & $1.227(0.574-2.621)$ & 0.597 & & \\
\hline Number of pulmonary segments sampled: $\geq 2$ (reference one segment) & $0.701(0.301-1.633)$ & 0.410 & & \\
\hline
\end{tabular}

a diagnosis of exclusion. Therefore, alternative sampling including lung biopsies should be considered early in patients with hematologic malignancies.

Non-HIV, non-hematologic malignancy patients had a diagnostic yield that was in between the HIV patient and hematologic malignancy group. The most pertinent finding in this group was that the most commonly identified pathogen was Mycobacteria tuberculosis. This may be reflective of the endemic nature of tuberculosis in our population in Singapore [12], as well as the nature of the immunosuppression. This finding is corroborated by the presence of radiological evidence of cavitation in $11 \%$ of our patients and the trend towards increased diagnostic yield if cavitation was indeed present.

Complication rate was significant at $14.7 \%$ but was entirely self-limiting. There was a trend towards a higher rate in patients with higher co-morbidity burden and in those who were hypoxic at presentation. Co-morbidities are likely to impact the effect of moderate sedation on the cardio-respiratory system. Hypoxemia may be exacerbated by the introduction of saline for lavage and the degree of decruitment from bronchoscopic suctioning.

Our study also confirmed earlier data that prognosis of immunocompromised patient with pulmonary infiltrates was guarded and varied with underlying cause of immunosuppression. The all-cause 30-day and 90-day mortality ranged from 1.7 and $6.8 \%$ in HIV patients to 17.4 and $28.3 \%$ respectively in those with hematologic malignancy. Prior data showed a 30-day mortality in haematology patients to be $22 \%$ [13] and in neutropenic patients to be $26 \%$ [14]. In a mixed aetiology study, the 30 -day mortality was $7 \%$ in non-hematologic malignancy and $19 \%$ with hematologic malignancy [15]. This reflects the severity of illness that immunocompromised patients with pulmonary infiltrates have and should serve as an impetus to continue to improve bronchoscopic sampling and laboratory testing. Symptoms and radiological findings (besides the trend in presence of cavitation) also did not impact diagnostic yield in our study. Therefore, identifying patients who are unlikely to get a bronchoscopic diagnosis on the basis of only clinical presentation may be challenging. Delaying diagnosis due to a negative BAL result may also risk clinical deterioration.

Limitations of this study include the retrospective design. However, the fact that the data was extracted from a prospective bronchoscopy database directly populated by endoscopists' reports ensured completeness of data. In addition, procedure details were collected in a standardized format. Sample size may also have lacked statistical power to detect factors associated with complications because of the low complication rate. Finally, this data was limited to a single institution study. However, this meant that BAL sampling and microscopic testing was performed in a standardized manner.

\section{Conclusion}

Flexible bronchoscopy with BAL retains a role in the management of immunocompromised patients presenting with lung infiltrates especially in establishing a confirmed microbiological diagnosis. A diagnosis is possible in $60.8 \%$ and the complications are largely self-limiting. However, the diagnostic yield varies with underlying cause of immunosuppression and alternative sampling should be considered early in patients with hematologic malignancies because of poor results with BAL. This group with haematologic malignancy has a high 90-day mortality and delayed diagnosis risk clinical deterioration. Tuberculosis appears to be an important pathogen in endemic regions especially in the non-HIV, non-hematologic malignancy group. Aspergillus was the other commonly identified pathogen via culture and Galactomannan assay. Viruses accounted for $40.5 \%$ of positive diagnosis and this finding often leads to limited modification in clinical management. Our data show 
both the utility and limitations of BAL in the approach to immunocompromised patients presenting with lung infiltrates. This data will serve as the foundation on which newer therapeutic strategies such as transbronchial cryobiopsy can be evaluated.

\section{Abbreviations}

BAL: Bronchoalveolar lavage; Cl: Confidence interval; CT: Computed tomography; CTCAE: Common Terminology Criteria for Adverse Events; HIV: Human immunodeficiency virus; ICU: Intensive care unit; IQR: Interquartile range; OR: Odds ratio; SD: Standard deviation

\section{Acknowledgments}

This study was supported by the SingHealth Duke-NUS Academic Clinical Programme, SingHealth Duke-NUS Academic Medical Centre.

\section{Funding}

This study was supported by the SingHealth Duke-NUS Academic Clinical Centre AM-ETHOS Duke-NUS Medical Student Fellowship (Duke-NUS MSF) Award 2017 and the Department of Respiratory and Critical Care Medicine, Singapore General Hospital, Singapore.

\section{Availability of data and materials}

Datasets analysed for this study are available from corresponding author on reasonable request.

\section{Authors' contributions}

RC was involved in conceptualizing the study, data acquisition, analysis and manuscript preparation. NSHN participated in data acquisition and assisted in manuscript preparation. NVN analysed the data and assisted in manuscript preparation. DA was involved in conceptualizing the study, data analysis and manuscript preparations. All authors read and approved the final manuscript.

\section{Ethics approval and consent to participate}

Data was rendered non-identifiable with removal of patient's name, identification card number and date of procedure. Waiver of consent was approved by SingHealth Centralised Institutional Review Board. Approval Reference: 2011/350/C

\section{Consent for publication}

Not applicable.

\section{Competing interests}

The authors declare that they have no competing interests.

\section{Publisher's Note}

Springer Nature remains neutral with regard to jurisdictional claims in published maps and institutional affiliations.

\section{Author details}

${ }^{1}$ Duke-NUS Medical School, Singapore, Singapore. ${ }^{2}$ Salmaniya Medical Complex, Manama, Bahrain. ${ }^{3}$ Centre for Quantitative Medicine, Duke-NUS Medical School, Singapore, Singapore. ${ }^{4}$ Department of Respiratory and Critical Care Medicine, Singapore General Hospital, Academia Building Leve 3, 20 College Road, S169856, Singapore, Singapore.

\section{Received: 9 October 2018 Accepted: 4 February 2019}

\section{Published online: 26 February 2019}

\section{References}

1. Rañó A, Agustí C, Benito N, Rovira M, Angrill J, Pumarola T, Torres A. Prognostic factors of non-HIV immunocompromised patients with pulmonary infiltrates. Chest. 2002;122(1):253-61.

2. Jepson SL, Pakkal M, Bajaj A, Raj V. Pulmonary complications in the non-HIV immunocompromised patient. Clin Radiol. 2012;67(10):1001-10.

3. Rubin LG, Levin MJ, Ljungman $P$, Davies EG, Avery $R$, Tomblyn M, Bousvaros A, Dhanireddy S, Sung L, Keyserling H, Kang I. 2013 IDSA clinical practice guideline for vaccination of the immunocompromised host. Clin Infect Dis. 2014;58(3):e44-100.

4. Rosenow EC, Wilson WR, Cockerill FR. Pulmonary disease in the immunocompromised host (first of two parts). Mayo Clin Proc. 1985;60(7):473-87.

5. Du Rand IA, Blaikley J, Booton R, Chaudhuri N, Gupta V, Khalid S, Mandal S, Martin J, Mills J, Navani N, Rahman NM. British Thoracic Society guideline for diagnostic flexible bronchoscopy in adults. Thorax. 2013;68:i1-i44.

6. National Cancer Institute. Cancer Therapy Evaluation Program Protocol Development Website for Common Terminology Criteria for Adverse Events. [Internet] U.S. Department of Health and Human Services. 2017. Available from: https://ctep.cancer.gov/protocoldevelopment/electronic applications/docs/CTCAE_v5_Quick_Reference_5x7.pdf. [cited 2018 May 4]

7. Charlson ME, Pompei P, Ales KL, Mackenzie CR. A new method of classifying prognostic comorbidity in longitudinal studies: development and validation. J Chronic Dis. 1987:40(5):373-83.

8. Baughman RP, Dohn MN, Frame PT. The continuing utility of bronchoalveolar lavage to diagnose opportunistic infection in AIDS patients, Am J Med. 1994;97(6):515-22.

9. Danés C, González-Martín J, Pumarola T, Rañó A, Benito N, Torres A, Moreno A Rovira M, de la Bellacasa JP. Pulmonary infiltrates in immunosuppressed patients: analysis of a diagnostic protocol. J Clin Microbiol. 2002;40(6):2134-40.

10. Vélez L, Correa LT, Maya MA, Mejía P, Ortega J, Bedoya V, Ortega H. Diagnostic accuracy of bronchoalveolar lavage samples in immunosuppressed patients with suspected pneumonia: analysis of a protocol. Respir Med. 2007;101(10):2160-7.

11. Brownback KR, Simpson SQ. Association of bronchoalveolar lavage yield with chest computed tomography findings and symptoms in immunocompromised patients. Ann Thorac Med. 2013;8(3):153-9.

12. Regional Office for South-East Asia, World Health Organization. Bending the curve - ending TB: Annual report 2017. [Internet] WHO Regional Office for South-East Asia. 2017. Available from: http://www.who.int/iris/handle/10665/ 254762. [cited 2018 May 8]

13. Hohenadel IA, Kiworr M, Genitsariotis R, Zeidler D, Lorenz J. Role of bronchoalveolar lavage in immunocompromised patients with pneumonia treated with a broad spectrum antibiotic and antifungal regimen. Thorax. 2001;56(2):115-20.

14. Peikert T, Rana S, Edell ES. Safety, diagnostic yield, and therapeutic implications of flexible bronchoscopy in patients with febrile neutropenia and pulmonary infiltrates. Mayo Clin Proc. 2005;80(11):1414-20.

15. Sampsonas F, Kontoyiannis DP, Dickey BF, Evans SE. Performance of a standardized bronchoalveolar lavage protocol in a comprehensive cancer center. Cancer. 2011;117(15):3424-33.

16. Reichenberger F, Dickenmann M, Binet I, Soler M, Bolliger C, Steiger J, Brunner F, Thiel G, Tamm M. Diagnostic yield of bronchoalveolar lavage following renal transplantation. Transpl Infect Dis. 2001;3(1):2-7.

17. Rañó A, Agustí C, Jimenez P, Angrill J, Benito N, Danes C, Gonzalez J, Rovira M, Pumarola T, Moreno A, Torres A. Pulmonary infiltrates in non-HIV immunocompromised patients: a diagnostic approach using non-invasive and bronchoscopic procedures. Thorax. 2001;56(5):379-87.

18. Taggart S, Breen R, Goldsack N, Sabin C, Johnson M, Lipman M. The changing pattern of bronchoscopy in an HIV-infected population. Chest. 2002;122(3):878-85.

19. Jain P, Sandur S, Meli Y, Arroliga A, Stoller J, Mehta A. Role of flexible bronchoscopy in immunocompromised patients with lung infiltrates. Chest. 2004;125(2):712-22.

20. Bissinger $A L$, Einsele $H$, Hamprecht $K$, Schumacher $U$, Kandolf $R$, Loeffler J, Aepinus C, Bock T, Jahn G, Hebart H. Infectious pulmonary complications after stem cell transplantation or chemotherapy: diagnostic yield of bronchoalveolar lavage. Diagn Microbiol Infect Dis. 2005;52(4):275-80.

21. Hofmeister CC, Czerlanis C, Forsythe S, Stiff PJ. Retrospective utility of bronchoscopy after hematopoietic stem cell transplant. Bone Marrow Transplant. 2006:38(10):693-8.

22. Boersma WG, Erjavec Z, van der Werf TS, de Vries-Hosper HG, Gouw ASH, Manson WL. Bronchoscopic diagnosis of pulmonary infiltrates in granulocytopenic patients with hematologic malignancies: BAL versus PSB and PBAL. Respir Med. 2007;101(2):317-25.

23. Burger CD. Utility of positive bronchoalveolar lavage in predicting respiratory failure after hematopoietic stem cell transplantation: a retrospective analysis. Transplant Proc. 2007:39(5):1623-5.

24. Cordani S, Manna A, Vignali M, Tascini C. Bronchoalveolar lavage as a diagnostic tool in patients with hematological malignancies and pneumonia. Infez Med. 2008;16(4):209-13. 
25. Hummel M, Rudert S, Hof H, Hehlmann R, Buchheidt D. Diagnostic yield of bronchoscopy with bronchoalveolar lavage in febrile patients with hematologic malignancies and pulmonary infiltrates. Ann Hematol. 2008;87(4):291-7.

26. Shannon VR, Andersson BS, Lei X, Champlin RE, Kontoyiannis DP. Utility of early versus late fiberoptic bronchoscopy in the evaluation of new pulmonary infiltrates following hematopoietic stem cell transplantation. Bone Marrow Transplant. 2010;45(4):647-55.

27. Kottmann RM, Kelly J, Lyda E, Gurell M, Stalica J, Ormsby W, Moon K, Trawick D, Sime PJ. Bronchoscopy with bronchoalveolar lavage: determinants of yield and impact on management in immunosuppressed patients. Thorax. 2011;66(9):823.

28. Gilbert CR, Lerner A, Baram M, Awsare BK. Utility of flexible bronchoscopy in the evaluation of pulmonary infiltrates in the hematopoietic stem cell transplant population-a single center fourteen-year experience. Arch Bronconeumol. 2013;49(5):189-95.

29. Kim SW, Rhee CK, Kang HS, Lee HY, Kang JY, Kim SJ, Kim SK, Lee SY, Kim YK, Lee JW. Diagnostic value of bronchoscopy in patients with hematologic malignancy and pulmonary infiltrates. Ann Hematol. 2015;94(1):153-9.

30. Svensson T, Lundström KL, Höglund M, Cherif H. Utility of bronchoalveolar lavage in diagnosing respiratory tract infections in patients with hematological malignancies: are invasive diagnostics still needed? Ups J Med Sci. 2017;122(1):56-60

31. Sakata KK, Klassen CL, Bollin KB, Grys TE, Slack JL, Wesselius $L$, Vikram HR. Microbiologic yield of bronchoalveolar lavage specimens from stem cell transplant recipients. Transpl Infect Dis. 2017;19(3):e12684.

Ready to submit your research? Choose BMC and benefit from:

- fast, convenient online submission

- thorough peer review by experienced researchers in your field

- rapid publication on acceptance

- support for research data, including large and complex data types

- gold Open Access which fosters wider collaboration and increased citations

- maximum visibility for your research: over $100 \mathrm{M}$ website views per year

At $\mathrm{BMC}$, research is always in progress.

Learn more biomedcentral.com/submissions 